\title{
Cartografias da sala de aula: o fracionamento das relações étnico-racializadas
}

\author{
Classroom cartographies: the fractionation of ethnic- \\ racialized relationships
}

Cartografía en el aula: la fraccionamiento de las relaciones étnico- racializadas

MARIA DE FÁTIMA GARCIA (iDa

MicARLA SiLVA DE AZEVEDOiDb

ANA MARIA PeREIRA AIRES (iDc

\section{Resumo}

Esta pesquisa aborda o racismo na sala de aula numa turma do $4^{\circ}$ Ano do Ensino Fundamental em uma escola pública na microrregião do Seridó Potiguar, estado do Rio Grande do Norte. O estudo investiga a relação entre crianças negras e nãonegras sob a ótica dos estudos decoloniais e pressupostos da cartografia social da sala de aula por meio da metodologia de ensino do Trabalho em Grupo. O estudo caracteriza-se como qualitativo quanto a abordagem, e exploratório quanto aos objetivos. Os resultados apontam comportamentos excludentes adotados por crianças não-negras e professores, sendo que a cor da pele (de)marca os lugares de (não)pertencimento dos alunos negros gerando visível tensionamento no processo

\footnotetext{
a Universidade Federal do Rio Grande do Norte. E-mail: ufrn01488@ufrn.edu.b

b Universidade Federal do Rio Grande do Norte. E-mail: silvamicarla14@gmail.com

cUniversidade Federal Rural do Semi-Árido. E-mail: ana.aires.rn@gmail.com 66 Rev. Caminhos da Educação: diálogos, culturas e diversidades, Teresina, v. 3, n. 2, p. 
Cartografias da sala de aula: o fracionamento das relações étnico-racializadas

de constituição da identidade negra e consequente perda do potencial escolar dessas crianças.

Palavras-chave: Racismo. Cartografias da sala de aula. Alunos negros.

\begin{abstract}
This research addresses racism in the classroom in a 4th grade elementary school class in a public school in the microregion of Seridó Potiguar, state of Rio Grande do Norte. The study investigates the relationship between black and non-black children from the perspective of decolonial studies and assumptions of social cartography in the classroom through the methodology of teaching Group Work. The study is characterized as qualitative in terms of approach, and exploratory regarding objectives. The results indicate exclusionary behaviors adopted by non-black children and teachers, and the skin color demarcates the places of (non)belonging of black students creating visible tension in the process of constitution of black identity and consequent loss of the school potential of these children.
\end{abstract}

Keywords: Racism. Classroom cartography. Black students.

\title{
Resumen
}

Esta investigación aborda el racismo en el aula en una clase del $4^{\circ}$ año de la escuela primaria en una escuela pública de la microrregión Seridó Potiguar, estado de Rio Grande do Norte. El estudio investiga la relación entre niños negros y no negros desde la perspectiva de los estudios descoloniales y supuestos de la cartografía social del aula a través de la metodología de enseñanza del Trabajo en Grupo. El estudio se caracteriza por ser cualitativo en términos de enfoque y exploratorio en términos de objetivos. Los resultados señalan comportamientos excluyentes adoptados por niños y profesores no negros, y el color de piel (de) marca los lugares de (no) pertenencia de los estudiantes negros, generando tensión visible en el proceso de constitución de la identidad negra y consecuente pérdida de potencial escolar de estos niños.

Palabras clave: Racismo. Cartografía del aula. Estudiantes negros. 


\section{Introdução}

O racismo é um ato de hostilidade que negligencia os direitos humanos, não sendo a educação antirracista ainda suficientemente trabalhada nas escolas, principalmente nas séries iniciais do Ensino Fundamental, conforme preconizado pelas Leis $n^{\circ} .10 .639 / 03$ e $n^{\circ} .11 .645 / 08$. O presente estudo, desenvolvido junto a uma turma do $4^{\circ}$ ano do Ensino Fundamental de uma escola da rede pública de ensino, localizada na microrregião do Seridó Potiguar, objetivou investigar como ocorre o convívio entre crianças brancas e negras no espaço escolar tendo por intuito entender a dinâmica de constituição de uma cartografia social da sala de aula (AUTOR) através da metodologia de ensino baseada nos Trabalhos em Grupo, no cotidiano dos que não possuem o fenótipo padronizado pela cultura da branquitude.

A tessitura teórica do estudo se fez pela perspectiva da decolonialidade, com base nas ideias de Quijano (2010), Fanon (2008); pelo entendimento do racismo entre crianças a partir de Cavalleiro (2001), Koltai (2004), Nogueira (1985); e, pelos estudos de Santos (2012) que elucidam a hierarquização dos espaços, lugares e zonas fronteiriças invisíveis destinados ou negados ao povo negro. Além destes Acselrad (2018), subsidia os estudos da cartografia social praticada pelas comunidades tradicionais, dentre outros, que tratam, respectivamente da subalternização construída e atribuída à população negra e outras populações e etnias que se afastam do padrão eurocêntrico.

Sabe-se que é na escola e, principalmente, nas etapas da Educação Infantil e Ensino Fundamental que surgem as primeiras manifestações agressivas ao outro dito como "diferente" e por consequência, muitas dessas atitudes são associadas à cor da pele, reproduzindo-se, portanto, um paradigma de superioridade entre brancos e negros (KOLTAI, 2004). Isto posto, problematiza-se: Como a cartografia social da sala de aula expõe o racismo praticado a crianças negras, visto a partir da metodologia de ensino do Trabalho em Grupo?

Essa metodologia de ensino foi escolhida por se entender que nos trabalhos em grupo os estudantes comungam o alcance dos mesmos objetivos, são 


\section{Cartografias da sala de aula: o fracionamento das relações étnico-racializadas}

interdependentes entre si, mas preservam a liberdade para exercer sua autonomia intelectual à medida que desenvolvem habilidades cognitivas de estudo. Trabalhos em grupo pressupõem interação entre os alunos, atitude colaborativa e aprendizagem recíproca.

De acordo com as habilidades da Base Nacional Comum Curricular é necessário "Identificar direitos civis, políticos e sociais expressos na Constituição de 1988 e relacioná-los à noção de cidadania e ao pacto da sociedade brasileira de combate a diversas formas de preconceito, como o racismo" (BRASIL, 2017, p. 431). Esse preceito aparece nos anos finais do Ensino Fundamental, mas deve ser trabalhado por toda a Educação Básica, desde a Educação Infantil, utilizando-se quando necessário o recurso da transposição didática dos conhecimentos científicos para os conhecimentos escolares. Entende-se que os conhecimentos e tecnologias acumulados pelas culturas, dentre estas a dos povos africanos, sejam trazidos ao currículo para que alunos negros se vejam representados nos feitos de seus ancestrais e os não-negros aprendam a respeitar a história e os valores civilizatórios do povo negro e afro-brasileiro.

Metodologicamente, optou-se pela pesquisa de abordagem qualitativa pois esta “[...] trabalha com o universo de significados, motivos, aspirações, crenças, valores e atitudes, o que corresponde a um espaço mais profundo das relações, dos processos e dos fenômenos [...]” (MINAYO; DESLANDES; GOMES, 2002, p. 14). A entrevista semiestruturada foi realizada junto à professora a fim de se compreender como a instituição e os sujeitos a ela pertencentes se posicionavam em relação à problemática do racismo. Os dados foram produzidos por meio de diário de campo e das respostas a um questionário aplicado a dezoito alunos da turma, sujeitos da pesquisa, com base em Gil (2008). Esse questionário teve a finalidade de investigar o fracionamento das relações raciais, tendo como foco duas meninas negras na relação com os demais estudantes da sala de aula; A técnica de observação com registro das 
vivências em diário de campo provou ser fundamental, pois, a pesquisa qualitativa não deve se limitar ao material discursivo (MINAYO, 1993).

\section{Espaços periféricos ocupados por crianças negras na cartografia social da sala de aula}

Os espaços físicos são ocupados de maneiras muito diferentes quando as referências voltam-se às dimensões geográficas globais ou locais. Os continentes, países, cidades, o centro e as periferias foram construídos a partir do estabelecimento de zonas limítrofes político-administrativas, mas também, de fronteiras invisíveis, fundadas em critérios classificatórios e hierarquizantes. O ponto de vista que se apresenta nas narrativas elaboradas a partir do eurocentrismo compôs o panorama geopolítico e ideológico do colonialismo perpetuado durante séculos pelo continente europeu. Apesar da independência de quase todas as colônias sob o jugo europeu há um processo vigente de recolonialidade (WALSH, 2009), sustentado pelo capitalismo e suas políticas neoliberais em abrangência planetária. Por outro lado, observa-se um crescente movimento de contraposição social com vistas à formação de uma mentalidade igualmente planetária que se fundamenta nos princípios da decolonialidade (QUIJANO, 2010).

O global perpassa o local (o contrário também é verdadeiro) e as concepções hegemônicas permeiam a ambientação das relações sociais nas salas de aula. Este estudo sinaliza que nas escolas, especificamente, no interior das salas de aula, a colonialidade se mantém preservada nos currículos, nos comportamentos sociais e até mesmo nas metodologias de ensino. Santos (2012) ao se referir às espacialidades das relações raciais, afirma que as experiências vividas por pessoas negras hão de ser compreendidas diante de uma:

Complexidade (espacial, temporal e social) das regras das relações raciais no padrão brasileiro: há espaços, lugares, momentos, contextos de interação, nos quais, através de comportamentos (que são fruto de aprendizado) subjetivos (às vezes bastante objetivos!) a presença negra pode ser aceita, brindada e até valorizada, ou, por outro lado, tolerada, não aceita, reprimida ou repelida (SANTOS, 2012, p. 58). 


\section{Cartografias da sala de aula: o fracionamento das relações étnico-racializadas}

Espaços sociais em que prevalecem o esporte (exemplo, o futebol), certos tipos de arte (o grafite, o samba, o hip-hop), o trabalho assalariado de menor poder aquisitivo, as pessoas negras são bem aceitas e até requeridas. Porém, atividades, trabalhos e profissões, que envolvem atributos de maior status social, ou requerem o uso do aparato intelectual, são subjetivamente negadas às pessoas negras: Santos (2012) postula que existem fronteiras objetivas e subjetivas que permeiam as dinâmicas sociais e este texto acompanha os deslocamentos, agrupamentos e isolamentos experienciados pelas crianças naquilo que aqui estamos denominando de

\section{Cartografia Social da Sala de Aula.}

A cartografia social, conceito emprestado do campo da Geografia - é utilizado pelas comunidades tradicionais - ribeirinhos, castanheiras, quilombolas - dentre outros e, segundo Acselrad (2018), não retrata apenas o espaço, mas sim, modos de vida de uma comunidade sendo que o que está em jogo é o "território enquanto terreno disputado material e simbolicamente" (ACSELRAD, 2018, p.5). A cartografia social se constitui como o mapa produzido pelos integrantes da comunidade com o poder de se auto representar segundo aquilo que se entende serem suas identidades específicas, retirando-se do Estado o poder de monopólio sobre os usos que se fazem do território, sobretudo, se quem mapeia o território é o próprio Estado ou empresas privadas.

Neste estudo, faz-se a transposição da Cartografia Social que implica dinâmicas territoriais de comunidades povoadas por significativo quantitativo populacional, para a pequena comunidade de uma sala de aula do quarto ano do Ensino Fundamental. $\mathrm{Na}$ fase exploratória (primeira fase da pesquisa) a observação mostra-se relevante para se entender a dinâmica, os comportamentos, os (não-)lugares e deslocamentos, fronteiras visíveis e invisíveis que ali subjazem na conformação paulatina da cartografia social da sala de aula.

A metodologia de ensino conhecida como Trabalho em Grupo, muito utilizada tanto na educação básica quanto no ensino superior, foi o objeto de estudo 
escolhido para se entender a constituição dessa cartografia devido à premissa em desenvolver a autonomia intelectual dos alunos, a cooperação e a aprendizagem colaborativa. A partir de uma proposta de trabalho, consubstanciada numa temática ou em projetos de pesquisa escolar, ou, ainda, na resolução de problemas envolvendo conceitos trabalhados, os alunos podem ser agrupados livremente com critérios antecipadamente definidos pela professora. No entanto, estudantes das etapas iniciais e finais do ensino fundamental e médio, bem como jovens adultos do ensino superior, são frequentemente expropriados desse ambiente de trocas e aprendizagens, posto que a ação de agrupar-se, com frequência representa momento de tensão, constrangimento, dor e exclusão.

A falta de empatia para com o outro encontra justificativa na falta de compromisso com os estudos, notas baixas dentre outras razões, porém, os estereótipos são a causa mais frequente. E, para estudantes negros e negras, a fronteira invisível e subjetiva é a cor da pele, porém, mascarada sob o estigma da incompetência do aluno, argumento este usado por professores e reproduzido pelos colegas de classe referenda a ideia racista de que a criança negra não compartilha das mesmas capacidades cognitivas das demais, não-negras, numa clara alusão à superioridade branca (mesmo que inconsciente, afinal, tanto o racismo quanto a colonialidade são estruturantes da mentalidade social).

Para a realização dos trabalhos em grupos há uma movimentação do mobiliário escolar na sala de aula: carteiras são deslocadas do lugar de origem, alunos que se sentam distantes ou próximos se juntam para iniciar a atividade. Vozes, convites para compor o grupo, troca de olhares e rapidamente as parcerias se formam.

O campo dos estudos da História da Educação evidencia que a arquitetura das escolas e salas de aula, historicamente, organizaram seus espaços entre centros e periferias. No caso da sala de aula, a espacialidade composta pelas mesas dos estudantes posicionadas em fileiras (da frente até o fundo da sala), uma atrás da outra, mesa do professor à frente e o centro da sala - mais próximos ao professor ou professora - predominantemente, é ocupado pelos alunos mais participativos, com melhor desempenho em avaliações, e quase sempre, brancos ou não-negros. Ali se localiza, sócio-cartograficamente, o centro do poder, para onde se voltam as Rev. Caminhos da Educação: diálogos, culturas e diversidades, Teresina, v. 3, n. 2, p. 66-87, mai./ago. 2021 


\section{Cartografias da sala de aula: o fracionamento das relações étnico-racializadas}

interações e diálogos entre colegas considerados com melhor desempenho, bem como, o maior cuidado e atenção das professoras ou professores com a aprendizagem dos seus alunos. Os espaços laterais e o fundo da sala ficam restritos aos alunos que não se identificam com o padrão anteriormente citado, e seus ocupantes são conhecidos como "a turma do fundão". São os esquecidos, vistos como bagunceiros, incompreendidos e descomprometidos com a vida acadêmica. Alguns exercem certo tipo de liderança, mas uma liderança marginal, não validada pelo "centro".

A esses espaços, denominamos espaços periféricos da sala de aula, porque entendemos que assim são fabricados pelo poder (ou poderes) que emana(m) do centro, numa evidente concepção centrista de sala de aula configurada pela espacialidade física, social e suas fronteiras subjetivas invisíveis. Essa organização traz em si, subliminarmente, um discurso, e uma evidência nem sempre percebidos, tampouco dotados de neutralidade, como afirmam os autores:

Para Agustín Escolano (1998), nem o espaço, nem o tempo escolares são dimensões neutras do ensino, simples esquemas formais ou estruturas vazias da educação. Ao contrário, [...] operam como uma espécie de discurso que institui, em sua materialidade, um sistema de valores, um conjunto de aprendizagens sensoriais e motoras e uma semiologia que recobre símbolos estéticos, culturais e ideológicos. Como pedagogias, tanto o espaço quanto o tempo escolar ensinam, permitindo a interiorização de comportamentos e de representações sociais. Nessa perspectiva, atuam como elementos destacados na construção social (e histórica) da realidade (ESCOLANO e VINÃO, 1995 apud FILHO e GONÇALVES, 2000, p.19-20).

Os alunos que se posicionam à periferia das salas de aula sofrem influência e influenciam a constituição da cartografia da sala, sendo ao mesmo tempo vítimas do racismo, mas também, tensionadores do centro do poder à medida que a prática da exclusão exige constantes agenciamentos e (rápidas) tomadas de decisões com vistas a reagrupamentos a fim de evitar aproximações com colegas indesejáveis, meramente, por conta da cor da pele negra.

Na Figura 1, podemos ver como estão dispostas as crianças em uma sala de aula, cartograficamente convencional: carteiras enfileiradas, mesa da professora à frente. 
Figura 1- Cartografía convencional da sala de aula

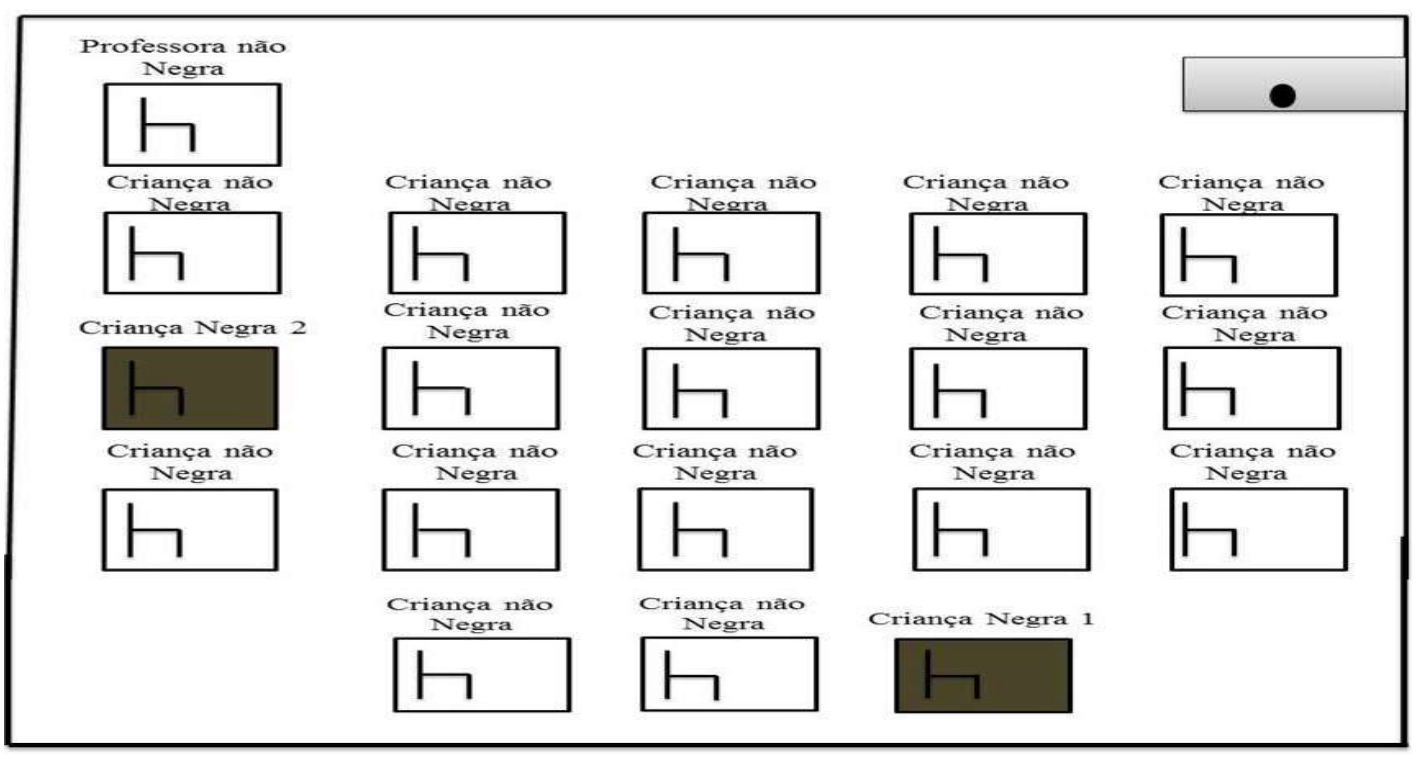

Fonte: Autoras (2020).

$\mathrm{Na}$ turma de $4^{\circ}$ ano, em tese, estão matriculadas apenas duas alunas negras, uma de pele com tonalidade bem escura denominada respectivamente, neste texto Criança Negra 1 e outra de pele mais clara, denominada Criança Negra 2. Ao ver a Figura 1 nota-se que a criança de pele negra mais clara, senta-se na lateral esquerda, logo na segunda fileira de carteiras. A aluna de pele negra mais escura, cabelos mais crespos senta-se na última carteira dos fundos, intuindo-se que, mesmo na cartografia do grande grupo ela já se encontra separada, fracionada em relação aos demais, ocupando um espaço periférico, não apenas pelo local físico da sala de aula, mas sim pelo ambiente hostil a que está relegada. Isso, certamente, se fará mais contundente e explícito, quando a professora exigir que as atividades sejam feitas conforme a proposta metodológica de trabalhos em grupos, como veremos a seguir.

\section{A naturalização do racismo frente ao fracionamento escolar}

Para fins deste estudo entende-se fracionamento escolar como forma da constituição da cartografia social do racismo, evidenciado pela cisão e ruptura do tecido microssocial composto pelas relações que se estabelecem na sala de aula (ou 


\section{Cartografias da sala de aula: o fracionamento das relações étnico-racializadas}

nos demais espaços físicos da escola) entre crianças negras, não-negras e professores não-negros.

Ao se considerar a sala de aula enquanto espaço de interações, faz-se necessário compreender que o racismo estabelecido nesse lócus não se derivou da realidade atual, mas é um reflexo dos paradigmas que já foram construídos no decorrer da história do colonialismo e do racismo estrutural (ALMEIDA, 2019), vigentes na sociedade brasileira. De acordo com Cavalleiro (2001) as próprias nomenclaturas negro e índio eram utilizadas pelos colonizadores anglo-europeus para justificar a desumanidade e coisificação do "outro", ao passo que percebiam na branquitude uma forma de assegurar suas posições de privilégios e ainda legitimizar a superioridade étnica.

A constituição de 1988, em vigor, declara que "Todos são iguais perante a lei, sem distinção de qualquer natureza, garantindo-se aos brasileiros e aos estrangeiros residentes no país a inviolabilidade do direito à vida, à liberdade, à igualdade, à segurança e à propriedade" (BRASIL, 2016, p.13). Apesar do exposto, torna-se preocupante, que as práticas racistas não apresentem índices de desaceleração dentro das próprias escolas e, sobretudo, entre as novas gerações, constituindo-se como violência simbólica e causando, consequentemente, sentimentos de angústia e fracasso aos atingidos, pois:

Deve-se notar que, em igualdade de outras condições, o negro ou a pessoa escura sempre luta com desvantagem. Não se devem subestimar as dificuldades que 0 indivíduo escuro (ou negroide) tem de enfrentar, seus sofrimentos e angústias, seus prejuízos morais e materiais (NOGUEIRA, 1985, p.79).

Considerando a temática do racismo na sala de aula e as múltiplas negligências constata-se que, conforme defendido por Cavalleiro (2001), a escola é um dos locais onde mais se apresentam as discriminações racistas em relação à etnia, haja vista que é lá que as crianças têm um maior contato com outras descendências e culturas diferentes da sua. Por conseguinte, quando os educandos não são levados a refletirem o porquê da recusa ao outro, a ideologia dominante acaba se reproduzindo e 
contribuindo para a construção de um espaço de "vencedores" e "perdedores", em um processo contínuo de recolonialidade.

Nesse contexto, impõe-se um ambiente de superioridade, no qual as crianças negras são levadas a se "igualar" às brancas, ou, como afirma Franz Fanon (2008) mesmo tendo a pele negra, há que se viver e agir como pessoa de cor e ideologia branca, ou, simbolicamente, usar máscaras brancas, com vistas a se evitar a ruptura no tecido social, ou o fracionamento das relações e assim serem excluídas dos ciclos de amizade que compõem a sala de aula. Possivelmente, a menina negra, "de pele mais clara, cabelos lisos, cuja vestimenta era de melhor nível aquisitivo, e que apesar da pouca idade, já fazia uso de cosméticos e maquiagem" (diário de campo da pesquisadora), já entendeu o funcionamento dos lugares sociais para negros e não negros e, especificamente, a cartografia da sua própria sala de aula. Com base nisso, faz uso do artifício 'máscara branca' postulado por Fanon, e assim se integra aos grupos, imaginando que a eles tem pertencimento.

A cartografia da sala de aula é dinâmica e, com a movimentação das carteiras, move-se e visibiliza-se também o preconceito e o racismo. No contexto de agrupamento, em um primeiro momento proposto pela professora, ao se analisar a Figura 2, pergunta-se: Qual dos quatro grupos, mesmo aqueles com poucas pessoas, incluíram a Criança Negra 1 para realizar o trabalho em grupo?

Figura 2- Cartografia dos grupos na sala de aula 


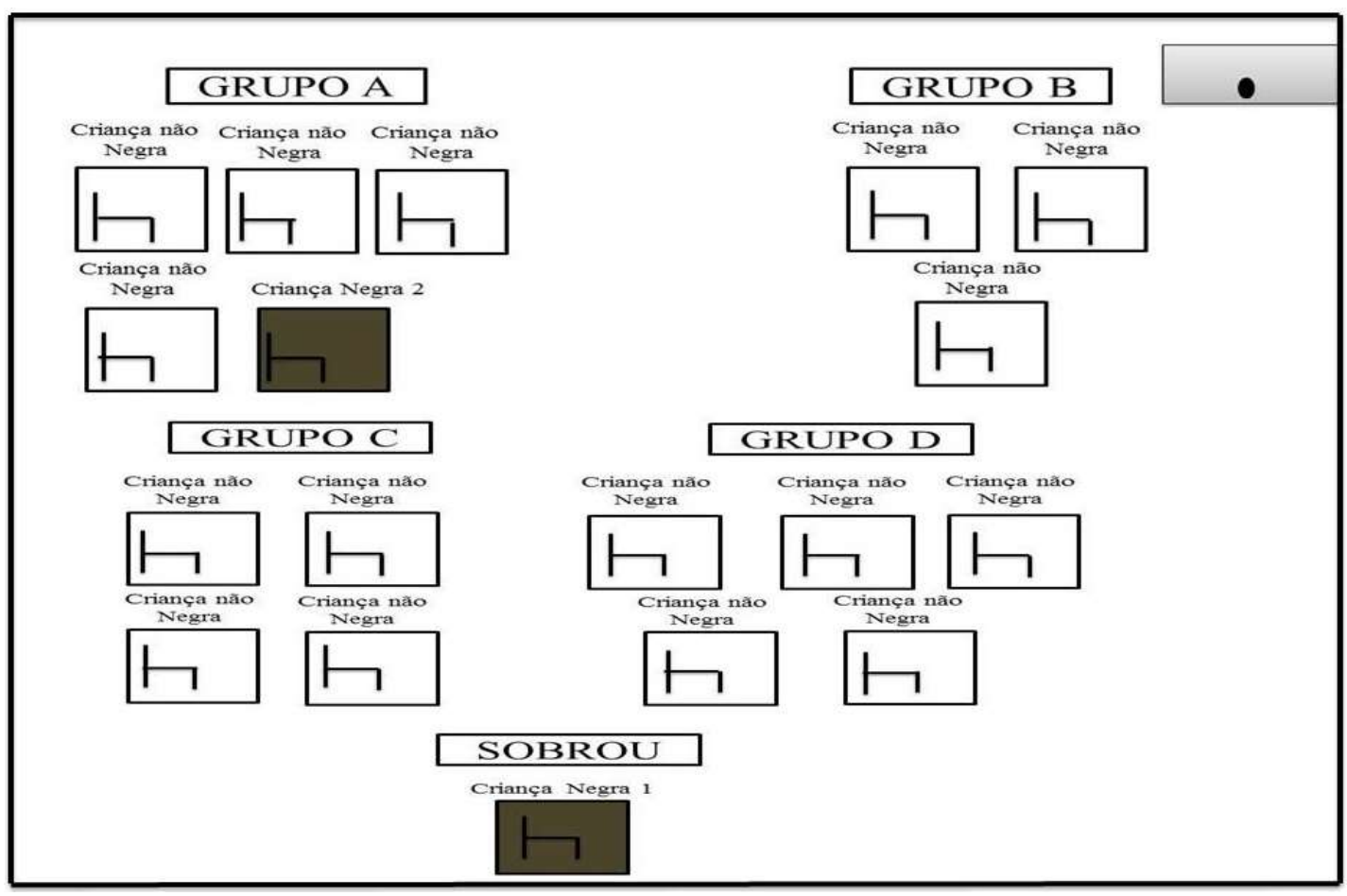

Fonte: Autoras (2020).

Conforme registros em Diário de Campo, a professora encaminhou duas propostas de atividade grupal. Na primeira, a professora solicita que as crianças formem grupos e, enquanto todos se reuniam, a criança negra 1 (pele mais escura) ficou sozinha e sem colegas, mesmo havendo vagas nos grupos B (com 3 crianças) e $\mathrm{C}$ (com 4 crianças). Somente depois que todos os grupos estavam formados, a criança negra 1 junta-se ao grupo dos meninos, por exigência da professora. Ou seja, não houve acolhida deliberada por nenhum dos grupos, mas sim, obrigatoriedade a aceitar. E aqui, invisivelmente, há outra fronteira subjetiva a se considerar: a da exclusão pelo gênero. $\mathrm{Na}$ fase compreendida entre 9 e 11 anos, as crianças se agrupam em torno do gênero: Meninas com seu grupo de meninas, meninos com amigos meninos, cuja alusão popular ao desenho animado ficou conhecido como a turma da Luluzinha e a turma do Bolinha, criações da cartunista americana Marjorie Henderson Buell, na década de 1930. Nesse contexto de atividade grupal, é perceptível o constrangimento dessa criança que não tem lugar no grupo de seu gênero, sendo 
obrigada a compor o grupo dos meninos e estes, a contragosto, sendo (quase) coagidos a aceitá-la!

A subalternização é reforçada no segundo momento em que a mesma metodologia de ensino é utilizada. A enunciação de fala demonstra ser mais conveniente para uma aluna não negra realizar um trabalho em grupo com outra criança, igualmente não-negra, mesmo que a menina negra tenha feito o pedido, antecipadamente. A fala transcrita, intitulada Criança Negra 1, foi proferida no momento anterior à organização dos grupos para a realização da segunda atividade, quando solicitado novamente o agrupamento pela docente dessa vez em duplas. Analisa-se a seguinte situação:

CRIANÇA NEGRA 1 - Trabalho em grupo de novo? Eu não tenho ninguém para fazer esse trabalho não. Você quer fazer o trabalho comigo? Eu ainda não combinei com ninguém. Acho que vai ser muito legal se fizermos nós duas, como você ainda não combinou com ninguém também, pode fazer comigo, não é? É bom que a gente já senta perto e não tem nem o trabalho de levantar a cadeira.

Então, a criança não-negra, sentada a frente da menina negra, responde:

CRIANÇA NÃO-NEGRA - Eu? Bom, espera... É que eu acho que não vai dar certo eu ir com você, porque agora que eu me lembro que eu já tinha combinado com outra pessoa. Fulanooo, você quer fazer o trabalho comigo? Ah, desculpa, eu vou fazer meu trabalho com outra pessoa, realmente eu não tinha combinado, mas agora fazer o que né? Você pode ir sozinha, essa tarefa não é muito difícil, qualquer um consegue fazer só.

Diante do diálogo, é possível observar que a criança negra 1, já antecipando que não seria bem sucedida, lança mão não apenas do convite, mas do argumento positivo "vai ser muito legal se fizermos nós duas", soando como um clamor desesperado para ser aceita e incluída. Ela demonstra que tem conhecimento que a colega não combinou a dupla com outra criança: "como você ainda não combinou com ninguém também, pode fazer comigo, não é?"; Fundamenta seu pedido com base no espaço da cartografia física da sala e a proximidade do mobiliário (a cadeira escolar) no espaço: “É bom que a gente já senta perto e não tem nem o trabalho de levantar a cadeira", mas, nada, nada mesmo, é argumento suficiente para que ela, negra, seja aceita pela criança não-negra. 


\section{Cartografias da sala de aula: o fracionamento das relações étnico-racializadas}

Santos (2012) afirma que as organizações espaço-temporais das relações raciais mistura no cotidiano das pessoas, por um lado, horizontalidades, integrações, igualdade e simetrias. E, por outros, verticalidades, diferenças e hierarquias e assimetrias. A mesma menina não-negra que nega o pertencimento da colega negra ao trabalho em dupla, pode ser a mesma em que ambas brincam divertidamente no pátio da escola. Mas, em momentos em que o acesso ao conhecimento é valorado por meio da avaliação e quantificado em pontos para a nota, a diferença é "transformada em desvantagem ou vantagens desiguais entre esses grupos” (SANTOS, 2012, p. 44). Esse ordenamento social é recorrente na vida das pessoas negras quando se trata "de acesso às riquezas que a sociedade produz (acesso à educação, emprego, saúde, conhecimento, e seus instrumentos de produção, posições de poder, etc)" (Idem, p. 44) e, infelizmente, essa configuração social é ensinada e aprendida na escola. A metodologia de ensino baseada no trabalho em grupo, aqui analisada, demonstra essa evidência.

Koltai (2004), psicanalista e pesquisadora dos estudos relacionados ao migrante e aos refugiados, explica que o receio ao desconhecido nem sempre é considerado racismo, sobretudo quando a criança é muito pequena e o rosto estranho ao que ela conhece (familiares, amigos muito próximos) lhe soa como ameaça. A essa fase do desenvolvimento infantil ela denomina de xenofobia infantil. Conquanto, tal fato torna-se alarmante, quando os indivíduos já se conhecem e mesmo assim, negligenciam ou excluem a figura do colega, transformando assim a xenofobia infantil, em racismo ativo:

Para que a xenofobia infantil se transforme em racismo ativo é preciso um discurso que nomeie o estrangeiro a ser odiado e esse discurso é sempre social. Para que haja racismo verdadeiro, para além dos preconceitos pessoais e antipatias circunstanciais, é necessário um discurso que autorize a pulsão agressiva, nomeie o bode expiatório tornando-o inapto a qualquer identificação (KOLTAl, 2004, p.93).

Assim, é possível atribuir que há racismo desde a infância, uma construção paulatina que se fortalece a medida em que os discursos e ações sociais o autorizam e o normalizam. Em outras palavras, mesmo com a superação de alguns paradigmas Rev. Caminhos da Educação: diálogos, culturas e diversidades, Teresina, v. 3, n. 2, p. 66-87, mai./ago. 2021 
hegemônicos, a sociedade não mudou completamente o cenário de proeminência das ações e discursos de superioridade branca, constituído séculos atrás. Então, pode-se afirmar, que esse poder ainda se apresenta nas inter-relações e reacomoda-se, a partir da "recolonialidade" (WALSH, 2009), ao contexto social escolar, quando se acentua nas salas de aula, através dos trabalhos em grupos e dos currículos, ações de controle dos conflitos causados pelas questões raciais. O propósito de incluir grupos historicamente excluídos, tendo como norte a estabilidade social capitalista, traz danos à aprendizagem e prejudica fortemente o desenvolvimento da identidade de crianças negras.

Levando-se em consideração as ideias de Nogueira (1985) acerca das lutas travadas pelas pessoas negras socialmente sempre em desvantagem, torna-se possível reconhecer que os maiores conflitos no que diz respeito à inter-relação de diferentes etnias não ocorre entre os indivíduos indígenas e os de origem europeia, mas sim entre os de etnia negra e branca. Na medida em que a criança se percebe discriminada, seja pelos próprios colegas ou mesmo por causa do "padrão" imposto, ela tende a querer se inserir, mesmo que isso signifique a negação da sua identidade, valores e costumes e tudo passa a ser "negociável" para a sua aceitação reverberando atitudes de embranquecimento conforme nos alerta Fanon (2008), e também, Walsh em relação ao conceito de sociogenia:

A sociogenia pode ser entendida como uma pedagogia própria de autodeterminação e autolibertação, com quatro enfoques ou componentes medulares: despertar, estimular a auto-agência e ação, facilitar a formação de subjetividade e autorreflexão e formentar e revitalizar racionalidades político- éticas "outras" que se distanciam da razão modernoocidental-colonial, se enraízam e apontam um agir para a liberdade, para a transformação e a criação de estruturas sociais e condições de existência radicalmente distintas (WALSH, 2009, p. 26).

A dificuldade encontrada nas vivências de aprendizagem, como por exemplo, na realização de metodologias como as do Trabalho em Grupo incide nos processos de desenvolvimento da Inteligência, causando atrasos na aprendizagem e, em consequência, "nos processos de seleção escolar ainda parece difícil a priori que uma criança negra seja capaz de grandes voos cognitivos. As crianças mais claras são mais estimuladas a isso [...]" (CAVALLEIRO, 2001, p. 61). 
Essa hierarquia racializada, conforme explica Walsh (2009; SANTOS, 2012) ocorre quando a fenotipia europeia torna-se o centro do processo e em contrapartida os negros são compreendidos enquanto entidades negativas e desvalorizadas, mantidos presos à condição de subalternidade por diversos fatores, tais como: a trajetória histórica que ainda está impregnada na atualidade; a imposição de um "padrão" tido como superior; a naturalização das práticas racistas, a existência de fronteiras subjetivas invisíveis, dentre outros. A cartografia social da sala de aula é composta por alunos e professores, portanto, faz-se necessário entender como a professora dessa turma, imersa nesse contexto se posiciona, é o que veremos a seguir.

\section{Como a professora percebe o racismo na cartografia da sala de aula}

A partir do que vimos até aqui se faz necessário investigar como a professora se insere nessa cartografia. Para tal, em entrevista fez-se a ela, a seguinte questão: "Você já percebeu alguma manifestação racista entre os seus alunos ou mesmo eles já demonstraram alguma falta de companheirismo uns aos outros"?

PROFESSORA - Racismo? Não, graças a Deus aqui não existe isso. Essas crianças sempre tiveram uma amizade muito grande, elas sempre se ajudam em tudo. São grandes amigos, veja, todo mundo percebe o quanto eles são companheiros. Lógico, que se eu perceber práticas racistas eu vou me meter e não vou permitir, mas não é o caso dessa escola e muito menos dessa sala de aula.

Pela análise da resposta é possível deduzir que a professora não percebe nenhum tipo de racismo, tampouco nota a negligência em relação às práticas racistas nessa cartografia social de sua sala de aula. Contudo, os dados demonstram que o fracionamento das relações étnicas, focalizando a Criança Negra 1 comprova-se a partir dos direcionamentos da aula, especificamente, na proposta metodológica do Trabalho em Grupo, conforme registro do momento em que a criança branca, não tendo ninguém para fazer o trabalho coletivo, não se se dispôs a fazê-lo com uma 
colega negra. Nessa cartografia a professora, por negligenciar o racismo (ainda que inconscientemente) protagoniza fortemente a agressão à autoestima e identidade da criança negra, à medida que dificulta o desenvolvimento cognitivo e, consequentemente, o processo escolar, pois como argumenta Cavalleiro "Acredita-se que o maior impedimento para a conclusão dos ciclos escolares não seria o ingresso no mercado de trabalho, mas a vivência dos processos intra-escolares" (CAVALLEIRO, 2001, p. 42).

Posteriormente à observação em relação ao ocorrido com os grupos, houve um breve diálogo com a professora, que, anteriormente, já havia respondido em entrevista afirmando que na sala de aula não havia racismo e que os estudantes eram muito unidos. As pesquisadoras, então relatam a ela o que fora registrado na observação empírica, obtendo-se a seguinte resposta:

PROFESSORA - Não, eles só fizeram isso, porque como eu não tinha avisado que iria ter a avaliação, eles escolheram formar duplas com quem tinha estudado. Mas, eu nunca vi por esse lado, nunca percebi nada. O que acontece é que essa menina negra, ela não costuma estudar muito para os trabalhos, sabe? Então, os colegas acabam não querendo formar dupla com ela.

$\mathrm{Na}$ fala da professora é possível perceber três aspectos da fronteira subjetiva relativa aos lugares de pertencimento das crianças negras, perpetuadas pelo racismo, que se objetiva, de forma invisível, na cartografia da sala de aula: Negação; Naturalização; Não-Percepção. A negação é um dado histórico, quando se trata do racismo, nesse sentido, a negação do racismo pela professora torna-se naturalizada. Racismo naturalizado deixa ser objeto da atenção das pessoas e, tampouco, fator de indignação e providências administrativas quando acontece. Racismo negado, não percebido e naturalizado torna-se prática, hábito, costume e cultura no cotidiano das salas de aula. As posturas racistas raramente encontram quem as confrontem, no entanto, a professora ao ser confrontada pelas pesquisadoras a partir da empiria, devidamente registrada, caracteriza sua justificativa com base em dois aspectos: julgamento implícito e defesa: O julgamento implícito está claro quando a professora atribui (des)compromisso da aluna com os estudos. A defesa se estabelece em relação aos demais estudantes, quando a professora afirma: “ela não costuma 
estudar muito para os trabalhos, sabe?" e defesa dos demais alunos: "Então, os colegas acabam não querendo formar dupla com ela”.

Parafraseando Spivack (2020), o subalterno (não) pode falar: A aluna está fracionada, separada, sozinha, vulnerável, constrangida, humilhada, portanto, silenciada, o que a torna invisibilizada. A criança negra 1 sente que ninguém a quer e sabe que não confiam em sua capacidade intelectual. Considerando a justificativa da professora, de que os demais estudantes não querem formar grupo com a criança negra pelo fato dela não ter estudado o suficiente para a prova, como se explica o fato de que, no primeiro trabalho em grupo, que não tinha valor quantitativo de avaliação (nota), os sujeitos e principalmente as demais meninas rejeitaram formar dupla com essa colega?

Por conseguinte, para se compreender um pouco mais sobre os lugares ocupados nessa cartografia social pela aluna negra e sua consciência identitária, foi aplicado um questionário para se compreender se a identidade em processo de formação estava se desenvolvendo fortalecida ou insegura e cambiante. Tomando-se como base imagens de duas bonecas, uma branca e outra negra, solicitava-se que os educandos marcassem as opções: 1. Como se enxergavam em relação ao pertencimento de cor-etnia; 2. A boneca que considerava mais bonita; 3. Qual dessas bonecas gostaria de ganhar de presente:

Figura 3- Questionário realizado com os estudantes

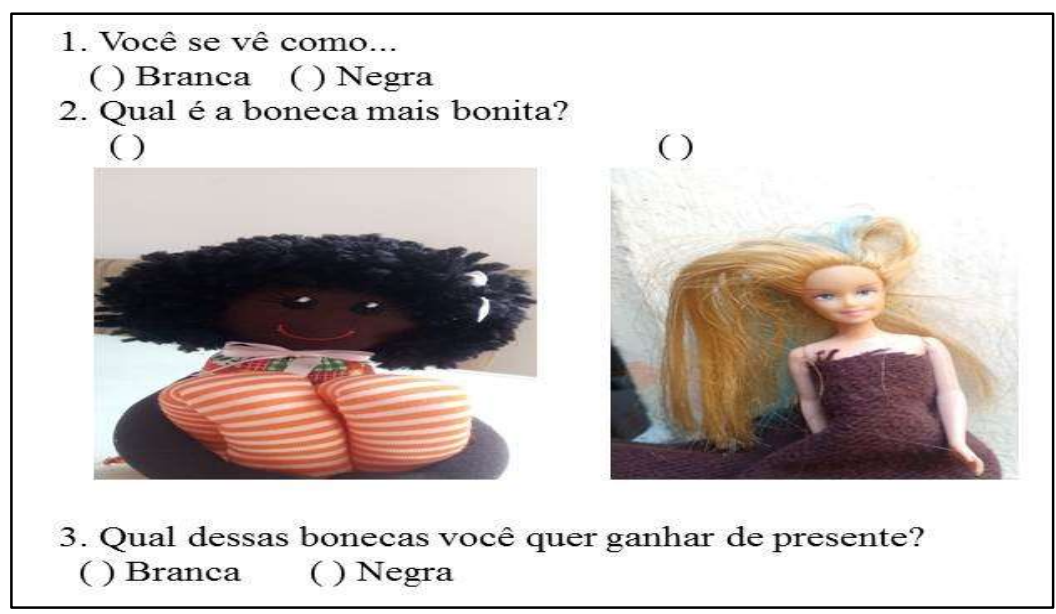

Rev. Caminhos da Educação: diálogos, culturas e diversidades, Teresina, v. 3, n. 2, p. 66-87, mai./ago. 2021 
Fonte: Autoras (2020).

Em resposta, a Criança Negra 1 - que foi ignorada pelos demais colegas quando da realização dos trabalhos em grupo - se autodeclarou negra, contudo, respondeu que considerava mais bonita a boneca branca, de olhos claros e cabelo liso, mesmo sabendo que sua aparência não se assemelhava ao daquela boneca. E, logo em seguida, ao responder qual das duas queria ganhar de presente, optou pela boneca branca de olhos azuis. Por meio do questionário foi possível evidenciar uma identidade bastante insegura, pois, a menina apesar de não se ver representada nos brinquedos apresentados, seu desejo estético está voltado aos padrões de beleza imposta pela cultura da branquitude a qual se impõe que são bonitas aquelas pessoas que têm um cabelo liso, são brancas e têm os olhos azuis. Notadamente, há uma desarticulação daquilo entre o que ela vê no espelho e o que é considerado "belo".

Essa é uma dimensão que permite aprofundar o problema existencial ontológico, particularmente dos descendentes africanos, um problema enraizado não só na desumanização do ser, mas também na negação e destruição de sua coletividade diaspórico-civilizatória e sua filosofia, como razão e prática de existência (WALSH, 2009, p. 14).

O pensamento de Walsh nos alerta para a necessidade de se adequar os currículos e as práticas pedagógicas, aqui se incluindo as metodologias de ensino, para que as crianças descendentes dos povos africanos encontrem seu lugar nas salas de aula, nos trabalhos em grupo, nas avaliações da aprendizagem, na interação com seus colegas e na atenção e cuidado de seus professores para que obtenham bom desempenho e sucesso escolar. A exclusão de crianças negras demarca lugares na cartografia social das salas de aula e sinaliza que elas não deviam estar ali, não são bem vindas.

\section{Considerações finais}

O estudo, em sua fase exploratória, originou-se da necessidade de compreender como se compõe a cartografia social da sala de aula e, em sua dinâmica, como o racismo é praticado na interação entre crianças negras, não-negras e professora de uma turma de quarto ano dos anos iniciais do Ensino Fundamental, tendo como foco a metodologia de ensino Trabalho em Grupo. Constatou-se que nas 


\section{Cartografias da sala de aula: o fracionamento das relações étnico-racializadas}

salas de aula os espaços físicos e simbólicos se compõem ao que denominamos de 'espaços periféricos da sala de aula'. Estes são entendidos como espaços marginais à atenção e cuidado da professora e relegados à exclusão das crianças negras evidenciados pela recusa das crianças não-negras em aceitá-las compor os trabalhos em grupo propostos pela professora. A pesquisa identificou que os trabalhos em grupo, cuja finalidade pressupõe a colaboração, o desenvolvimento intelectual e a aprendizagem recíproca entre todos os membros do grupo representam um espaço de poder ocupado pelos que dominam o centro dessa cartografia social, em cujos lugares crianças negras de pele mais escura não são bem-vindas.

Assim, fica evidente que, tal como na sociedade, as salas de aula estabelecem fronteiras subjetivas visíveis e invisíveis, nelas há lugares assegurados de pertencimento para pessoas não-negras que gozam de vantagens de acesso ao conhecimento, e desvantagem para as negras nesse e demais campos decorrentes do desenvolvimento intelectual. Assim, o mapa que compõem essa cartografia mostra o fracionamento nas relações sociais, a exclusão, humilhação, o domínio dos espaços e lugares ensinados para uns e a subalternidade para outros; $\mathrm{O}$ acesso ao conhecimento privilegia os não-negros e na mesma medida coloca os negros em situação de vulnerabilidade e desigualdade. Movimentos, deslocamentos físicos dos alunos e do mobiliário da sala de aula, comunicação oral e visual, enunciações, locais onde as crianças se sentam para assistir as aulas, naturalização do racismo advindos de professores acerca de práticas racistas vivenciadas entre as crianças denotam as fronteiras subjetivas visíveis e invisíveis e estas os lugares de (não) pertencimento de crianças negras na cartografia social da sala de aula.

Espaços periféricos na sala de aula vão além do sentar ao fundo e laterais afastados da sala; Ocupam os espaços periféricos da sala de aula, crianças que são deixadas à margem dos trabalhos em grupo, cuja metodologia de ensino pressupõe aprendizagem mútua, colaboratividade, desenvolvimento da autonomia intelectual. Os ocupantes desses espaços marginalizados pelo centro do poder povoarão, 
certamente, os mapas da evasão escolar e a ocupação de espaços de ocupações subalternas quando adultos, produzindo elevadas estatísticas da desigualdade social.

Ao final, uma nota para se refletir: Este texto foi escrito numa fase histórica de pandemia em que o mundo encontra-se devastado pelo Vírus Corona-19. As estatísticas se acentuam e mostram os índices de infecção e morte ilustrados pela cor da desigualdade: pretos, partos e indígenas. Quem sabe se tantas crianças dessas etnias não tivessem sido alijadas do sucesso escolar, o Brasil não exibisse números tão alarmantes da doença. Será o racismo, por contaminar mentalidades ao longo das gerações, um vírus mais difícil de ser combatido que o Covid-19?

\section{Referências}

ACSELRAD, Henri. Cartografia social e dinâmicas territoriais: marcos para o debate. 2018.

ALMEIDA, Sílvio. Racismo Estrutural. Coleção Feminismos Plurais, 2019.

FANON, Franz. Pele Negra, Máscaras Brancas. Salvador: EDUFBA, 2008.

FARIA FILHO, Luciano Mendes de; Diana Gonçalves Vidal. Os Tempos e os Espaços Escolares no Processo De Institucionalização da Escola Primária no Brasil. Revista Brasileira de Educaşão, nº.14 - ISSN 1413-2478 - Rio de Janeiro, RJ: 2000.

BRASIL. [Constituição (1988)]. Emenda Constitucional no 95, de 15 de dezembro de 2016. Altera o Ato das Disposições Constitucionais Transitórias, para instituir o Novo Regime Fiscal, e dá outras providências. Diário Oficial, v. 241, 2016.

MISTÉRIO DA EDUCAÇÃO. Base Nacional Comum Curricular. Brasília-DF: MEC, Secretaria de Educação Básica, 2017.

MINISTÉRIO DA EDUCAÇÃO. LEI No 10.639, DE 9 DE JANEIRO DE 2003. Brasília, DF. 2003.

MINISTÉRIO DA EDUCAÇÃO. LEI N ${ }^{\circ}$ 11.645, DE 10 DE MARÇO DE 2008. Brasília, DF, 2003.

CAVAlLEIRO, E. S. Racismo e Anti-Racismo na Educação. São Paulo: Selo Negro: 2001.

GIL, A.C. Métodos e Técnicas de Pesquisa Social. 6. ed. Ediitora Atlas SA, 2008.

KOLTAI, Caterina. O Estrangeiro, o Racismo e a Educação. Educação do Preconceito: ensaios sobre poder e resistência. Campinas/SP: Editora Alínea, p. 91-101, 2004.

MINAYO, M. C. S; DESLANDES, Suely Ferreira; GOMES, Romeu. Pesquisa Social: teoria, método e criatividade. Petrópolis: Editora Vozes Ltda, 2002. 
Cartografias da sala de aula: o fracionamento das relações étnico-racializadas

MINAYO, M. C. S. O Quantitativo-Qualitativo: Oposição ou Complementariedade. Cadernos de Saúde Pública, v. 9, n. 3, p. 239, 1993.

NOGUEIRA, O. Tanto Preto Quanto Branco: Estudos de relações raciais. São Paulo: USP, 1985.

QUIJANO, Aníbal. Colonialidade do poder e classificação social. In: SANTOS, Boaventura Santos e MENESES, Maria P. Epistemologias do Sul. São Paulo: Cortez, 2010.

SANTOS, Renato Emerson (Org). Questões Urbanas e Racismo. Coleção Negras e Negros: Pesquisas e Debates. Brasília, DF: 2012.

SPIVACK Gayatri Chakravorty Pode o Subalterno Falar? Belo Horizonte, UFMG: 2020.

WALSH, Catherine. Interculturalidade Crítica e Pedagogia Decolonial: In-Surgir, Re-Existir e Re-Viver. In. CANDAU, Vera Maria (org). Educação Intercultural na América Latina: entre concepções, tensões e propostas. Rio de Janeiro, 7 Letras, 2009, p. 12-43. 